\title{
Michel Tournier, Vendredi ou les limbes du Pacifique
}

\section{Gian Luigi Di Bernardini}

\section{(2) OpenEdition}

\section{Journals}

\section{Édition électronique}

URL : http://journals.openedition.org/studifrancesi/8082

DOI : 10.4000/studifrancesi.8082

ISSN : 2427-5856

\section{Éditeur}

Rosenberg \& Sellier

\section{Édition imprimée}

Date de publication : 1 juillet 2009

Pagination : 443

ISSN : 0039-2944

\section{Référence électronique}

Gian Luigi Di Bernardini, « Michel Tournier, Vendredi ou les limbes du Pacifique », Studi Francesi [En ligne], 158 (LIII | II) | 2009, mis en ligne le 30 novembre 2015, consulté le 10 janvier 2021. URL : http:// journals.openedition.org/studifrancesi/8082 ; DOI : https://doi.org/10.4000/studifrancesi.8082

\section{Ce document a été généré automatiquement le 10 janvier 2021.}

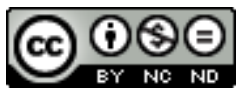

Studi Francesi è distribuita con Licenza Creative Commons Attribuzione - Non commerciale - Non opere derivate 4.0 Internazionale. 


\title{
Michel Tournier, Vendredi ou les limbes du Pacifique
}

\author{
Gian Luigi Di Bernardini
}

\section{RÉFÉRENCE}

MICHEL TOURNIER, Vendredi ou les limbes du Pacifique, Dossier par Marianne JAEGLÉ, Lecture d’image par Olivier TOMASINI, Paris, Gallimard, 2008 («Folioplus»), pp. 313.

1 Le Dossier (pp. 239-313) annexé à cette nouvelle édition de Vendredi ou les limbes $d u$ Pacifique, premier ouvrage de Michel Tournier, s'ouvre sur la lecture d'image d'olivier Tomasini. L'objet de l'analyse est la photographie Bocal au poisson rouge (1937) de Herbert List. Selon Tomasini, ce sont tout d'abord les ressemblances entre certains éléments de la biographie du photographe et l'aventure de Robinson qui justifient ce rapprochement. List a été en effet forcé, en tant que juif et homosexuel, d'abandonner l'Allemagne et, par là, de couper les ponts avec la civilisation occidentale, analoguement à ce qui arrive, fortuitement, à Robinson. Mais des raisons concernant la structure de la photo existent également. La photo reproduit un poisson rouge dans un bocal avec, à l'arrière-plan, le soleil qui apparaît derrière la mer. Le poisson rouge devrait symboliser l'esprit humain, prisonnier en même temps de son matérialisme et de son subjectivisme; le bocal empêche le poisson de sortir vers un ailleurs représenté par la lumière que la transparence de la vitre laisse filtrer. L'eau du bocal, transparente elle aussi, donne l'illusion au poisson d'être plongé dans la réalité alors qu'elle n'est pour lui, somme toute, qu'une illusion.

2 La deuxième partie du Dossier, Le texte en perspective (pp. 251-313), offre au lecteur une série d'éléments pour affronter la lecture d'un roman complexe comme celui-ci. Marianne Jaegle souligne le parcours scriptural de Tournier, sa formation philosophique, l'emploi du mythe comme moyen de transition entre la matière philosophique et la forme narrative du roman, les problèmes de la réécriture des mythes. 
3 Une fiche de lecture (pp. 310-313) pour les élèves de lycée clôture ce volume. 